\title{
Armadura de Ferro: fragmentos de solidão
}

\section{Agnes Sanfelici*}

\begin{abstract}
Resumo: Neste estudo destacamos os traços essenciais da obra de Altair Martins Como se moesse ferro com base no conceito de realismo maravilhoso e na idéia da vertente temática existencial-intimista. Foram selecionados dois contos para análise: "Como se moesse ferro" e "Humano".
\end{abstract}

Palavras-Chave: Conto; realismo maravilhoso; existencial-intimista.

\begin{abstract}
This research emphasizes the essential features of Altair Martins' work Como se moesse ferro, based on the concept of magic realism and on the ideas of the existential-intimist theme trend. Two short stories were selected and analysed: "Como se moesse ferro" and "Humano".
\end{abstract}

Keywords: Short Story; Magic Realism; Existentialism-intimism

"Mas o medo é mulher, trabalha o silêncio". Altair Martins

Altair Martins nasceu em Porto Alegre em 1975. Lançou seu primeiro livro de contos Como se moesse ferro pela WS Editor em 1999. Trata-se de uma obra que reúne onze contos que falam de tristes, pobres e solitárias vidas vividas a dois, de fraturas nos relacionamentos, do desenlace violento de quotidianos arrastados, moídos, macerados. Os contos que compõem essa obra são "Como se moesse ferro", "El espectro del sex-appeal", "Chefe de família", "Convite para uma vida secreta", "Tem um palhaço sorrindo", "Muito o que falar: 1. vindo querendo ir - 2. esperando querendo ir", "A Hora", "Advertência", "A história dos dias", "A marcha fúnebre" e "Humano". O conto "Como se moesse ferro" foi o ganhador em 1994 do prêmio Guimarães Rosa-Radio France Internationale.

Os contos de Como moesse ferro (1999) apontam para uma vertente existencialintimista, com nuances que se hibridizam com o mágico, o inusitado, o insólito e o estranho. Alguns aspectos que nos levariam a pensar nesses contos dentro de uma vertente mais existencial-intimista seria a focalização temática nas relações do indivíduo com o mundo ou consigo mesmo, configurada em relações afetivas de muita proximidade; ou ainda, a questão

\footnotetext{
* Agnes Sanfelici é Mestre em Teoria da Gramática - Lingüística pela UFSC e cursa o doutorado em Literatura Brasileira na UFRGS.
} 
da solidão, da incomunicabilidade com o outro, as perdas e desencontros, a ruína dos sonhos e desejos. São narrativas que enfatizam um mundo subjetivo, desvelando segredos que se escondem no interior do ser humano. Tratam de escavações de dores, de exposições de impotências e fragilidades, de medos, fraquezas, tristezas e perversões.

$\mathrm{Na}$ vertente existencial-intimista o que predomina é a investigação interior e a busca do auto-conhecimento, segundo Nádia Gotlib (1985, p.166) é "mais do que os fatos logicamente articulados, são as sensações vertiginosas que irrompem em determinados momentos, ocupando o primeiro plano da narrativa".

Em relação ao estranho, ao inusitado e ao mágico que aparece nos contos de Altair Martins, nos apoiamos no conceito de "realismo maravilhoso" do escritor cubano Alejo Carpentier. Este autor, a partir de uma viagem ao Haiti, maravilhado com a riqueza cultural dessa ilha, lugar onde o mágico e o maravilhoso se integravam à vida cotidiana, discute no prefácio de seu livro El reino de este mundo (1949) o conceito de realismo maravilhoso. De acordo com ele, o escritor para conseguir captar toda a variedade e grandeza cultural de um local como o Haiti, por exemplo, deve mudar sua posição ante a realidade. O racional não deve impedir que o mágico e o maravilhoso se integrem à realidade.

A partir dessa proposta de um realismo maravilhoso para a América, o escritor ampliando a discussão sobre o tema diz que "A América é o único continente onde diferentes eras coexistem", ou seja, em que os avanços tecnológicos da modernidade convivem com o primitivo. A fantasia sempre foi matéria prima da ficção, mas o realismo mágico na América Latina possui suas especificidades próprias.

O realismo maravilhoso na concepção de Alejo Carpentier coloca em questão a união de elementos díspares, procedentes de culturas heterogêneas, subvertendo, por sua vez, os padrões da racionalidade ocidental. O realismo maravilhoso foi, dessa forma, cunhado pelo escritor cubano para designar, não as fantasias do narrador, mas sim o conjunto de eventos que singularizam o contexto americano no ocidente (cf. CHIAMPI, 1980, p.32).

Os contos de Altair não podem ser considerados fantásticos de acordo com a concepção de Tzevan Todorov (1975). Para esse autor o fantástico só existe quando há hesitação por parte do leitor, que deve decidir entre uma explicação lógica ou uma aceitação do sobrenatural. No fantástico, há sempre que se perguntar se o que é visto é realmente um fato ou simplesmente fruto da imaginação. No caso de a solução dar-se pelas leis da realidade, abandona-se o terreno do fantástico em favor do estranho. Além disso, Todorov não aceita a leitura alegórica na categoria do fantástico. Nas narrativas de Altair Martins a apropriação de elementos mágicos, os acontecimentos insólitos são alegorias em que, por trás da 'realidade' 
ficcionalmente construída, instaura-se a problemática do maceramento das relações afetivas na contemporaneidade.

Os contos de Altair Martins não são narrativas da "poética da incerteza", calculadas para obterem o estranhamento do leitor. O realismo maravilhoso de Carpentier, diferentemente do fantástico de Todorov, desaloja o efeito do terror, da hesitação, do medo sobre o evento estranho ou insólito. No realismo maravilhoso, o insólito deixa de ser apavorante para incorporar-se ao real: o real é/está a/na realidade propriamente dita (cf. CHIAMPI, 1980, p.59).

As narrativas de Altair Martins são mixagens do realismo maravilhoso e do existencial-intimismo. No terreno mágico, no limiar entre o real e o insólito, revelam-se mecanismos de constituição daquilo que se toma por realidade, e assim, ocorrem processos em que a ilusão se faz realidade. Essas narrativas são alegóricas na medida em que, como bem colocou Cortazar (1991, p.386), quebram "seus próprios limites com essa explosão de energia espiritual que ilumina bruscamente algo que vai muito além da pequena e às vezes miserável anedota que conta."

Altair Martins em Como se moesse ferro (1999) vai muito além do simplesmente narrado, abre as portas para o reconhecimento de um mundo em que é impossível não instaurar uma espécie de ruptura com o quotidiano.

No que aproxima seus contos da tendência existencial-intimista, o contista exprime com muita intensidade o mundo subjetivo das personagens. Ele centra-se no ambiente interior das personagens desdobrando os inúmeros significados dos acontecimentos simples do dia-adia. Como bem colocou Bittencourt (1999, p.94-95) a narrativa existencial-intimista é, por um lado, um tipo de representação realista, amarrada a uma cadeia lógica de acontecimentos, unido a uma voz narrativa que orienta os rumos da história, ainda que em inúmeros momentos essa cadeia seja interrompida por monólogos interiores, fluxos de consciência. Por outro lado, essas narrativas ganham um tratamento onírico e metafórico em que é sugerido um mundo irreal.

Passemos à análise de dois contos de Como se moesse ferro para efeitos de uma melhor compreensão. No primeiro conto, "Como se moesse ferro", homônimo do título do livro, observa-se o esfacelamento do território comum da vida conjugal, de uma vida vivida a ferro. Trata-se da narrativa de um "homem que batia ferro como se moesse músculos" e "que batia ferro como se fosse mel" $(\mathrm{p}, 6)$. É também a história de uma mulher que deixou de desejar o seu ferreiro e passou a desejar o ourives. E depois descobriu que a sensibilidade e o 
brilho de sua vida estavam no ferro e não no ouro. Descobriu que embora gostasse do brilho do ouro havia nascido para o ferro.

Se tomarmos o sentido simbólico desses metais ferro e ouro, temos, no primeiro, a robustez, a dureza, a inflexibilidade. A idade do ferro é a idade dura. O ferro é o agente do princípio ativo que modifica a substância inerte. Já o ouro é considerado na tradição como o mais precioso dos metais: o metal perfeito. Tem o brilho da luz. Seria o produto do aperfeiçoamento de outros metais. Para os brâmanes, o ouro simboliza a imortalidade. Mas é também um tesouro ambivalente, pois pode simbolizar a perversão e a exaltação impura dos desejos $^{1}$.

Nesse sentido, o ourives, que chega à cidade e se torna o único amigo do 'homem que batia ferro', se identifica com a simbologia do ouro. Ele vem com o brilho da novidade, como aquele que manipula um material muito precioso e caro. Manipula o ouro e a seguir passa a manipular algo muito estimado pelo ferreiro: sua amada esposa.

Com relação ao estilo do autor, Altair Martins busca nas palavras jogar com a matéria e a sua ausência. Apropria-se de elementos sólidos, como ouro, ferro, espátula, colher, etc. Embora a matéria se faça presente, se possa tocá-la, se imprime nela a ausência causada pela insatisfação, pelo extremo estado sólido de solidão. A matéria utilizada serve como um elemento demolidor de mundos interiores fraturados pelas asperezas do dia-a-dia.

Além disso, utiliza o método de repetição de sentenças, o homem ferreiro (marido)

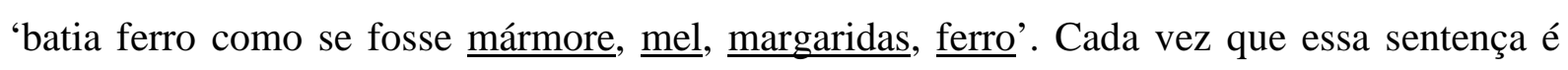
repetida, mudando-se o último sintagma nominal como exemplificado pelos sublinhados acima, são extraídas imagens que focalizam o interior da personagem, ou melhor, o humano do ser humano. Por exemplo: para representar a sapiência do ferreiro que sabia falar e, no entanto, não o fazia, visto que era um homem do silêncio sem ser mudo, o narrador traduz essa característica ao dizer que "era um homem que batia ferro como se fosse milho". Um homem capaz de ir às profundezas de si e do outro sem fazer alardes.

Dessa forma, na massa física das sentenças que se repetem, jorram elementos e sentimentos que possibilitam o deslizamento da narrativa pela exposição das fraturas das personagens. Percebe-se que é constituída uma relação nada arbitrária: a do vazio da linguagem (ferreiro não fala) e a repetição da linguagem (o narrador expõe os movimentos, dores e estados da personagem). Nesse vão, as palavras se perdem e se encontram formando

\footnotetext{
1. CHEVALIER, Jean \&GHEERBRANT, Alain. Dicionário de símbolos. Rio de Janeiro: José Olympio, 1990.
} 
um círculo de (des)encontros e perdas, abertas aos múltiplos sentidos de preenchimentos dados pelo leitor.

Apontando para o mesmo lugar, no locus da solidão desencadeada pelos processos de relacionamentos, delineia-se uma estranha figura: a da destruição violenta dada pela maçante rotina do cotidiano, que se mantém no gesto intermitente do não dizer e ao mesmo tempo de se repetir sem tréguas.

$\mathrm{Na}$ atitude da mulher diante do ferreiro e do ourives revela-se um problema do nosso tempo, isto é, uma impossibilidade ligada à dificuldade de manter vínculos afetivos estáveis e contínuos, o que leva as personagens a um sufocamento, um estado de desamparo recorrente. Esse desamparo traduz uma incomunicabilidade fundamental, a impossibilidade de nos traduzirmos inteiramente em face do outro, que nos coloca numa posição de solidão.

Esse conto configura-se num conto híbrido, que mistura características da vertente existencial-intimista e do realismo fantástico. Em princípio, nada de anormal na narrativa. Uma mulher casada com um ferreiro se apaixona por um ourives. Uma relação de adultério se desenvolve no decorrer da história. A seguir o arrependimento da mulher: a descoberta de que seu amor era mesmo do ferreiro e não do ourives. O pedido de perdão. O perdão concedido. Então fatos insólitos acontecem: depois do reencontro amoroso, o casal é encontrado no dia seguinte. A mulher aparece morta, enforcada por uma gargantilha com um pingente de coração em ferro (anteriormente, o ourives havia lhe dado um pingente de coração de ouro, como prova de sua amizade pelo ferreiro) e o homem (o ferreiro), ao lado dela, também morto, crivado de feridas e com uma lágrima de ouro no canto do olho esquerdo.

Os dois seriam enterrados juntos, seus corpos estavam duros e inseparáveis. Da fusão do ferreiro e sua mulher formou-se uma liga inseparável. Uma massa única e indivisível. Os corpos encontravam-se úmidos e quentes, pesavam juntos o equivalente a uma soma de seis fardos de ferro. E, do outro lado da cidade, outro homem também foi encontrado morto. Morto na cama com uma facada no peito. Era o ourives, e seu esôfago estava cheio de pequeninos corações de ferro e a sua nádega direita ferrada com um coração. Estava todo roxo, putrefato. Também pesava muito.

Em nenhum momento esses fatos levam o leitor a qualquer tipo de hesitação entre uma explicação lógica ou aceitação do sobrenatural. O que se vê em jogo por trás desse relato é uma metáfora: a do amor. Do mais profundo e denso amor. Da experiência quase destrutiva do amor que nos funde ao outro, que constrói uma trama invisível e nos modela como sujeitos. Segundo Piglia (2004, p.91-92): “o mais importante não se conta. A história é construída com o não dito, com o subentendido e a alusão". 
O não-dizível ou a 'outra história' possível dentre várias que poderíamos ler nesse conto é justamente o que só aparece no desfecho. No momento em que os corpos dos amantes são encontrados fundidos por uma liga inseparável, também se fundem as duas histórias paralelas do conto. E a história não contada é a metáfora do amor, que se revela na fusão dos corpos e sua transformação alquímica. Como a representação do ovo filosófico que simboliza o objetivo alquímico da conjunção: a união dos opostos.

Passemos à análise do segundo conto escolhido: 'Humano'. ${ }^{2}$ Em "Humano", Altair Martins detalha o flagelo de uma relação conjugal. $\mathrm{O}$ narrador nos mostra que era tanto o desgaste da relação que a "ponta dos dedos sofrera atrito de perder carne e viam-se as falangetas, já roídas também". ${ }^{3}$ Era tanto o desgaste da relação que a sentença é repetida três vezes consecutivas para enfatizar ao máximo a situação do casal.

O flagelo dessa relação conjugal vai sendo exposto e chega-se ao limite da dor, a ponto de não ser mais possível senti-la. Vinte e cinco anos de uma rotina que nunca deixou de faltar. Vinte e cinco anos de um gosto amargo de solidão a dois. Muitos anos de muita paciência: a dela. Mais muitos outros anos de muita paciência acumulada: a dele. Tudo por um fio. Um tênue e frágil fio.

Durante vinte e cinco anos o homem provara das piores comidas que impregnavam a sua boca com gosto de fel. Naquela noite, quando esperava pela pior de todas elas, surpreende-se ao comer da melhor que já havia experimentado em toda a sua vida. Sentiu tanta raiva, como se tivesse passado vinte e cinco anos sendo enganado: a mulher sabia cozinhar, por que escondera isso? A raiva feroz fez com que ele empunhasse um garfo ${ }^{4}$ de espetar grelhado e o cravasse fundo no ventre da mulher, deixando-a estirada no chão, abandonada. "É ser humano abandonar" (p.117).

O escritor utiliza-se mais uma vez de materiais sólidos (garfo, espátula, colher, etc) para representar a ausência. Ausência de comunicação e de encontro com o outro. A velha e conhecida solidão a dois. No desenvolvimento da narrativa, a cada novo e saboroso jantar, outros objetos vão sendo empunhados contra o corpo já dilacerado e dolorido da mulher. Afinal, como a própria mulher sentia: 'toda compreensão nasce mulher'. Embora calasse, sabia que fazia parte de sua natureza aceitar e até mesmo ninar toda essa dor. Mas o homem

\footnotetext{
2. Prêmio Guimarães Rosa, organizado pela Radio France Internacional, em 1999.

${ }^{3}$. MARTINS, Altair. Como se moesse ferro. Porto Alegre: WS editor, 1999, p.115.

${ }^{4}$. Interessante observar que para cada objeto que o homem espeta na mulher, o narrador utiliza notas de rodapé para explicar os anos e anos de falta de uso dos mesmos. Fica impresso no texto de Altair, via nota explicativa, todas as reclamações que nunca foram feitas, as mágoas que não se dissolveram, os ressentimentos pelo que poderia ter sido feito e não foi.
} 
não saía ileso de suas investidas violentas contra a mulher. A cada objeto jogado seu corpo também ia se desmanchando. Primeiro seus dentes caíram, depois seu nariz foi se despregando, deixando frisos de lesmas. A seguir foi a íris de seu olho direito que escorreu pelo rosto.

Nessa experiência de violação dos corpos é questionada a precariedade das relações afetivas contemporâneas e as próprias questões de violência subliminares que interditam os relacionamentos amorosos. O conto sugere uma reflexão do indivíduo e sua interioridade, e a sua impotência na relação com o outro. A adoção de elementos estranhos à ordem da natureza, como partes do corpo se despregando, outras como que derretendo, desvela processos psicológicos intrínsecos que costumam ser sub-reptícios no nível das aparências. $\mathrm{O}$ marido utiliza objetos pontiagudos e metálicos param transpassar o corpo da mulher, isto é, utiliza formas para atingir o nível da substância interior. O que vemos nesse arsenal culinário investido contra o corpo da mulher é também um processo gradual de desnudamento das aparências 'enganosas'. Os desníveis e insatisfações da relação conjugal vão emergindo a partir de um esgotamento de paciência, e a cada golpe desferrado contra a mulher, vêm à luz anos e anos de insatisfação acumulada do casal. Ambos machucados, dilacerados, desiludidos e enganados por seus próprios sonhos e desejos não realizados.

Ao final da narrativa, quando já não havia mais forças na mulher (nem no homem), o marido resolve alimentá-la. Ele o faz com calma, com servidão. E ao ser lento pôde sentir que sua brutalidade havia sido vencida. Sentiu-se humano e frágil. Pôde abrigar sua mulher em seus braços e alimentá-la com uma colherinha de chá, como se ela fosse um machucado e abandonado filhote de passarinho.

E com seu único olho, pela primeira vez conseguiu enxergá-la. Com seu único olho, conseguiu ver as coisas que sempre estiveram olhando para ele. Olhou sua mulher com seu único olho. E com seu único olho foi capaz de expressar o sentimento mais humano que um ser humano é capaz de sentir: amor. Amou-a como um homem pode amar uma mulher. Encheu-a de sorrisos. Naquela noite não jantaram como há vinte e cinco anos faziam. Amaram-se como é humano amar e talvez como nunca tenham conseguido em vinte e cinco anos de convivência.

Nessa atmosfera inusitada, o narrador vai construindo suas metáforas para mostrar que as impossibilidades (ou faltas de tentativas) de comunicar-se com o outro dentro de um relacionamento podem nos levar a distâncias (um do outro) insuperáveis. Essa narrativa de caráter alegórico retrata a vida tal como ela é - com todas suas fragilidades. Rompe-se com as ilusões da felicidade conjugal e com a de que a vida é sempre perfeitamente suportável e 
desejada. O leitor é impelido a destroçar todas as mentiras e enganos dos relacionamentos a dois e a defrontar-se com consigo mesmo de forma mais autêntica.

Ao tomarmos esses dois contos como objeto de análise, foi possível observar que, em ambas narrativas, Altair Martins perambula entre o existencial-intimista e o realismo fantástico. Ele representa um universo absurdo, em que as leis naturais são alteradas, mas que ao fim não surpreendem e nem colocam o leitor numa posição de hesitação diante dos fatos. $\mathrm{O}$ contista consegue com grande maestria converter quotidiano e magia em linguagem. Ao modo de Murilo Rubião, grande escritor brasileiro, pioneiro no tratamento da literatura fantástica, Altair parece ser um sujeito que acredita no que está além da rotina. Entranha-se no mundo onírico e, ainda, não se espanta com o mágico.

O escritor definitivamente alcança "o seqüestro momentâneo do leitor" trabalha com a eliminação do supérfluo. O que significa para Cortazar (1974, p.157), “a eliminação de todas as idéias e/ou situações intermediárias, de todos os recheios ou fases de transição que o romance permite e exige". Ao final, de forma proposital ou não, Altair Martins, consegue o que talvez seja mesmo o "maravilhoso" da literatura: enriquecer a vida de seus leitores, trazendo à tona reflexões sobre os tipos de posicionamento que temos diante da vida e seus inúmeros mistérios.

\section{Referências}

BITTENCOURT, Gilda Neves da Silva. O conto sul-rio-grandense: tradição e modernidade. Porto Alegre: Editora da UFRGS, 1999.

CARPENTIER, Alejo. El reino de este mundo. Madrid: Alianza Editorial, 2006.

CHIAMPI, Irlemar. O realismo maravilhoso. São Paulo: Perspectiva, 1980. (Coleção Debates)

CORTÁZAR, Julio. Valise de cronópio. São Paulo: Perspectiva, 1974. (Coleção Debates)

CORTÁZAR, Julio. Del cuento y sus alrededores. In: Pacheco Carlos \& Linares, Luis Barrera (comp). Caracas: Monte Ávila, 1991.

CHEVALIER, Jean \& GHEERBRANT, Alain. Dicionário de símbolos. Rio de Janeiro: José Olympio, 1990.

GLOTIB, Nádia. Teoria do conto. São Paulo: Ática,1985. (Princípios 2)

GOYANES, Mariano Baquero. Que es el cuento. Buenos Aires: Columba, 1967. 
MARTINS, Altair. Como se moesse ferro. Porto Alegre: WS Editor, 1999.

PIGLIA, Ricardo. Formas breves. São Paulo: Companhia da Letras, 2004.

TODOROV, Tzevan. As estruturas narrativas. São Paulo: Perspectiva, 1975. (Coleção Debates) 